\title{
Synthesis and Properties of Thermotropic Liquid Crystal Polymers with Main Chain Mesogenic Units
}

\author{
Robert W. LENZ \\ Chemical Engineering Department, University of Massachusetts, \\ Amherst, Mass. 01003, U.S.A.
}

(Received August 20, 1984)

\begin{abstract}
The molecular variables which control the structure-property relationships in thermotropic liquid crystalline polyesters are under investigation in this laboratory. A wide variety of polymers based on rigid, linear aromatic ester mesogenic units, with and without flexible or rigid spacers, have been prepared and characterized for their ability to form a liquid crystalline melt, the type of phase formed, their transition temperatures, and the morphology of the mesophase. Flexible spacers reduce both the melting and clearing temperatures, and the type and length of the spacer can determine whether either a nematic, cholesteric or smectic phase is formed. Variations in the structure of the rigid mesogenic group, both in the specific type and arrangement of the aromatic ester groups and the presence of pendant substituent, also cause profound changes in the properties of the mesophase melt formed.
\end{abstract}

KEY WORDS Thermotropic Polymers/. Liquid Crystalline Polymers / Mesogenic Groups / Flexible Spacers /

The history of main chain, liquid crystalline polymers is a relatively short one. In 1956 Flory predicted that rigid rod polymers should form lyotropic solutions at a critical concentration, ${ }^{1}$ and coincidentally, in the same year, lyotropic solutions of a polypeptide, which form a stable helical conformation in solution, were found to do so. ${ }^{2}$ However, little note was given to this observation, and it was not until the pioneering investigations of Kwolek and her coworkers in the du Pont Company on aromatic polyamides, that synthetic polymers with all linear para-substituted structures were found, fortuitously, to form lyotropic solutions, and that fibers spun from these solutions had remarkably high tensible strengths and bending modulii. ${ }^{3}$ This development apparently led to an immediate search within many fiber manufacturing companies for a fiber forming thermotropic polymer; that is, one which could be spun from a liquid crystalline melt to form fibers with similar extraordinary mechanical properties. This search resulted in a large number of patents, which began to issue in the middle of the 1970 s. $^{4}$

The first report in a scientific journal of the preparation and properties of a thermotropic, main chain polymer appears to be that by Roviello and Sirigu in $1975,{ }^{5}$ and this paper was followed shortly by a report of an independent study on the preparation and characterization of a series of thermotropic, main chain copolymers by Jackson and Kuhfuss. ${ }^{6}$ In both cases the polymers were polyesters, and indeed similar aromatic polyesters, which were subsequently found to be thermotropic, were reported in the patent literature by Goodman, McIntyre and coworkers as early as $1965 .^{7}$ Also, in 1972 Economy and coworkers described a family of aromatic copolyesters, which were recognized sometime later to form liquid crystalline melts. ${ }^{8}$

Hence, it may be said that the systematic study of thermotropic, main chain polymers was initiated only about ten years ago, so it is not suprising that our understanding of the structure-property relationships in such polymers is still quite superficial. At present, the most productive approach is still to prepare many different types of polymers containing rigid, linear units (referred to as mesogenic units), which should be capable of forming a liquid crystalline organization in the next, and attempt to 
deduce general relationship between their structures and their liquid crystalline properties. This empirical approach has been the one taken in our laboratory over the past five years.

Three principal methods have been used in our investigations ${ }^{9}$ on the synthesis of new thermotropic polymers, and in the studies carried out by other investigators, for modifying and controlling the properties of main chain liquid crystalline polymers; these are: (1) the use of nonrigid groups, termed flexible spacers, in combination with the rigid mesogenic groups in the main chain to reduce the aspect ratio of the latter; (2) the unsymmetrical placement of substituents on the mesogenic groups to disrupt the regularity of the repeating units within the polymer; and (3) the copolymerization of monomers containing either different types of mesogenic units (such as a naphthalene-based unit with a $p$-phenylene-based unit), or of monomers with either two different types of flexible spacers or two different types of rigid molecular structures in which one of the monomers is mesogenic and the other is not because of its non-linear structure. The effects of these types of variations in molecular structure on the liquid crystalline properties of their polymers will be discussed in the following sections.

\section{EFFECTS OF FLEXIBLE UNITS ON THERMOTROPIC PROPERTIES}

Several important observations and conclusions have resulted from our studies to date on the effects of the type and length of the flexible spacer unit, $R$, on the thermotropic properties of two series of polyesters which were based on a single type of mesogenic unit, an aromatic ester triad of the following structure: ${ }^{4,10,11}$

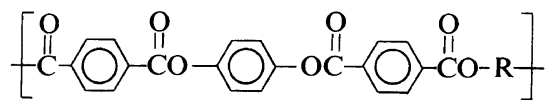

The results of these studies are compiled in Table I.

For the polymers in Table I containing polymethylene units, $\mathrm{R}=\left(\mathrm{CH}_{2}\right)_{n}$, those with spacers having 2, 4, and 6 methylene groups formed a nematic phase on melting, while those with the other methylene groups formed a smectic phase. ${ }^{11}$ The isotropization or clearing temperatures, $T_{\mathrm{i}}$, of these polymers showed a regular trend, with an oddeven effect, for the decrease in $T_{\mathrm{i}}$ with the length of
Table I. Effects of structure and length of flexible spacer unit on the liquid crystal properties of main chain polyesters

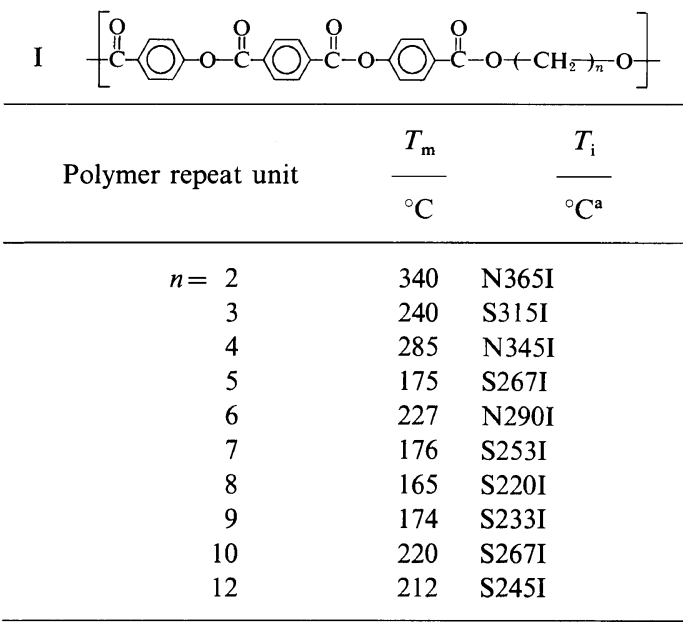

${ }^{\text {a }} \mathrm{N}$, nematic; S, smectic.

\begin{tabular}{|c|c|c|}
\hline \multirow{2}{*}{ Polymer repeat unit } & $T_{\mathrm{m}}$ & $T_{\mathrm{i}}$ \\
\hline & ${ }^{\circ} \mathrm{C}$ & ${ }^{\circ} \mathrm{C}^{\mathrm{a}}$ \\
\hline$n=1$ & 342 & N365I \\
\hline 2 & 185 & S222N288I \\
\hline 3 & 180 & S203N257I \\
\hline 4 & 121 & S211N245I \\
\hline 8.7 & 102 & N242I \\
\hline 13.2 & 91 & no l.c. \\
\hline
\end{tabular}

a $\mathrm{N}$, nematic, $\mathrm{S}$, smectic.

the flexible units, $\mathrm{R}$, up to $n=9$, but then $T_{\mathrm{i}}$ increased for the 9,10 , and 12 polymers as seen in the data in Table I. That is, the transition temperatures for the polymers with an even value of $n$ were generally higher than those with an odd $n$, as has been observed for several other series of polymers. ${ }^{12-14}$

From these results, we concluded that in this series of polymers, the longer flexible spacers render higher degrees of freedom to the mesogenic units which permit their alignment to form smectic layers. However, another possible explanation for the abrupt change from nematic to smectic order along the series may be that a conformational change of the polyalkylene spacer, from the fully extended trans conformation to the one with a central gauche 
unit, can occur for either the odd numbered or longer spacers. ${ }^{15}$ Such a conformational change would represent a higher energy state but it would stabilize the mesophase order.

The liquid crystal behavior of the polymers of the second series in Table I, that with the polyoxyethylene flexible units, also showed a very strong dependence on the length of the polyethyleneoxy spacer, $n .^{16}$ In this series, however, the polymers with shorter spacer units formed smectic as well as nematic phases, while the polymer with the longest spacer, $n=9$, in the series formed only a nematic phase. When the length of the polyoxyethylene spacer was further increased to $n=$ 13.2 (the next glycol monomer available at the time), the polymer did not form a liquid crystal phase. These observations emphasize the fact that the thermal stability, and the nature of the mesophase as well, strongly depend on a combination of both the structure and the length of the flexible spacer unit. The fact that a relatively short polyethyleneoxy spacer, one with $n=2$, causes the formation of a smectic phase indicates that the presence of an oxygen atom in the spacer may exert a specific polar effect, which strengthened the lateral intermolecular attraction between adjacent polymer chains, thereby helping the formation of smectic layers of the mesogens.

\section{Odd-Even Effect}

Recently, the type of odd-even effect which was noted above for the two series of polymers in Table I, has been studied in more detail by Roviello and Sirigu, ${ }^{17}$ by Blumstein and Thomas, ${ }^{18}$ and by Iimura and coworkers. ${ }^{19}$ The observation of the odd-even zig-zag variations in $T_{\mathrm{m}}$ and $T_{\mathrm{i}}$, as well as in the $\Delta S$ and $\Delta H$ values for these transitions, was common in all of these studies for polymers containing polymethylene spacers, but the cause of this effect does not, as yet, have a completely acceptable theoretical basis or understanding. However, similar trends are known for low molecular weight, thermotropic compounds containing $n$-alkyl terminal units, and the odd-even effect is, of course, well known for the melting points of both low molecular weight compounds and polymers with polymethylene structures. The latter are generally explained in terms of packing regularity in the crystal lattice.

For low molecular weight compounds expla- nations of these types of trends have been based on either the effects of changes in either molecular polarizability ${ }^{20,21}$ or on conformational effects resulting from the lengthening of the alkyl end groups and passing from even to odd terminal chain lengths. ${ }^{15,22-23}$ Most models assume that the entire molecule behaves as a rigid cylinder, and any change in geometry caused by rotation of bonds in the flexible unit that leads to violation of the cylindrical shape results in formation of the isotropic phase. That is, the explanation for a reduction of clearing temperature with increased spacer length is generally based on the effect of increasing the number of possible conformations of the long spacers with the resulting distortions of the cyclindrical shape of the molecule. ${ }^{21}$ According to the rigid-rod theory, an all trans conformation favors the liquid crystalline state, so the increased addition of gauche bonds would reduce the mesophase order. At high enough temperatures, the large number of gauche conformations present in the terminal groups of low molecular weight liquid crystalline compounds distorts the cylindrical shape of the molecule and destroys the liquid crystalline order.

The odd-even effect in low molecular weight compounds, on the other hand, may be induced by changes in the molecular polarizability of the mesogen in its normal and perpendicular components. ${ }^{20}$ The polarizability along the molecular axis is greater than that perpendicular to the axis for even chains but is about equal for odd chains if an all trans conformation is assumed. Stronger attractions exist between mesogens with even end groups, and consequently these compounds have higher clearing temperatures. A similar explanation can be offered for analogous odd-even effects on polymer melting points.

Such factors can lead to an alternation of $T_{\mathrm{i}}$ and an eventual damping of the effect itself. This interpretation is supported by an alternation of the order parameters that has been recently observed by ${ }^{13} \mathrm{C} \mathrm{NMR}^{24}$ and that was predicted by Marcelja and Pink $^{25}$ based on a modified Maier-Saupe theory. ${ }^{26}$ Their theoretical calculations have shown that the flexible end groups in such compounds play an active role in the formation of the mesophase and that intereactions between end groups and the mesogenic group cause an alternation of the order parameter, which in turn leads to the observed even- 
odd effects for $\Delta S_{\mathrm{i}}$.

\section{Pendant Group Flexible Units}

Long chain polymethylene groups can also be placed in the polymer as lateral or pendant substitutents on the mesogenic group, as well as a flexible spacer in the main chain, and similar results are obtained in terms of both the effect of unit length and odd-even structures on the thermal properties and type of liquid crystal phase formed. In recent investigations in our laboratory, two different series of polymers of this type were prepared and characterized for these effects, as follows:

Series I:

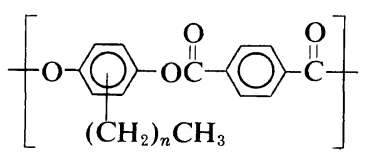

Series II:

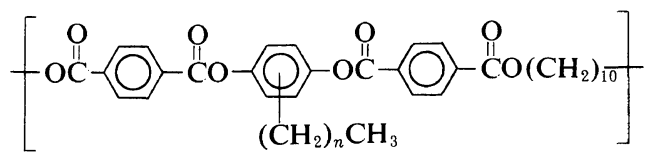

The first is based on the rigid rod polymer, poly(hydroquinone terephthalate), which has a melting point well above $600^{\circ} \mathrm{C}$. Substantial decreases in $T_{\mathrm{m}}$ and $T_{\mathrm{i}}$ values were only achieved when fairly long pendant alkyl substituents were used, so polymers containing $n$-alkyl groups ranging from the hexyl to the dodecyl ( $n=5$ to 11 in Series I) were prepared for this purpose, with the results shown in Table II. ${ }^{33}$

Because the polymer samples in Table II varied quite widely in molecular weight, as indicated by their solution viscosities, it is not possible to make exact comparisons of the effects of substituent length on their liquid crystalline properties, but as the data in Table II show, there was only a surprisingly small variation in both $T_{\mathrm{m}}$ and $T_{\mathrm{i}}$ with alkyl group length. What is also unexpected is that some of the polymers in Series I, particularly those with the decyl substituent, appear to form a smectic phase on melting, but additional characterization studies are needed to verify this conclusion.

For the Series II polymers containing a flexible decamethylene spacer and an aromatic triad ester mesogenic group, there was a very great effect of alkyl group size on both $T_{\mathrm{m}}$ and $T_{\mathrm{i}}$ as shown by the
Table II. Physical properties of the poly(2-n-alkyl-1,4-phenylene terephthalates), Series I

\begin{tabular}{|c|c|c|c|c|}
\hline \multirow{2}{*}{$\begin{array}{c}n \text {-Alkyl } \\
\text { Substituent }\end{array}$} & $\eta_{\mathrm{inh}}{ }^{\mathrm{a}}$ & $T_{\mathrm{m}}$ & $T_{\mathrm{i}}$ & $\Delta T$ \\
\hline & $\mathrm{dl} \mathrm{g}^{-1}$ & ${ }^{\circ} \mathrm{C}$ & ${ }^{\circ} \mathrm{C}$ & ${ }^{\circ} \mathrm{C}$ \\
\hline Hexyl & 0.52 & 277 & 323 & 46 \\
\hline Hexyl & 0.59 & 299 & 330 & 31 \\
\hline Hexyl & 1.32 & 295 & 340 & 45 \\
\hline Hexyl & 1.88 & 300 & 345 & 45 \\
\hline Heptyl & 0.48 & 257 & 302 & 45 \\
\hline Octyl & 0.47 & 257 & 307 & 50 \\
\hline Nonyl & 0.32 & 237 & 291 & 54 \\
\hline Decyl & 0.30 & 217 & 237 & 20 \\
\hline Decyl & 0.35 & 254 & - & - \\
\hline Decyl & 1.30 & 302 & 322 & 20 \\
\hline Decyl & 1.38 & 297 & 323 & 26 \\
\hline Decyl & 2.10 & - & 319 & - \\
\hline Undecyl & 0.37 & 228 & 292 & 64 \\
\hline Dodecyl & 0.25 & 217 & 277 & 60 \\
\hline
\end{tabular}

a Solution viscosity in $p$-chlorophenol at a concentration of $0.2 \mathrm{~g} \mathrm{dl}^{-1}$, at $45^{\circ} \mathrm{C}$.

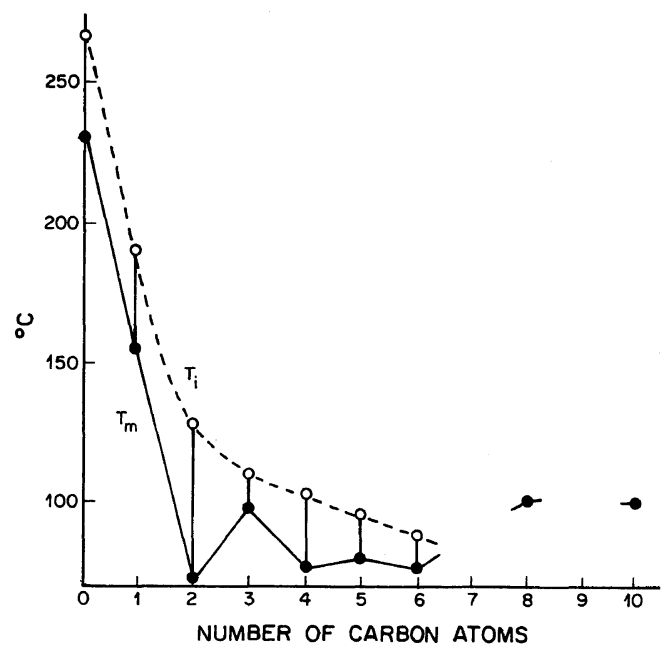

Figure 1. Dependence of transition temperatures on substituent group length for the Series II polymers.

data collected in Figure $1 .{ }^{34}$ As seen in this figure, on replacing a hydrogen atom with a methyl group in the Series II polymer, a remarkable decrease in melting point, from 231 to $154^{\circ} \mathrm{C}$, occurred. This temperature further decreased in an approximately odd-even, zig-zag fashion when the alkyl group was changed from methyl to hexyl. With further increase in the length of the pendant alkyl groups, the 
melting point increased only slightly and then leveled off. It is likely, therefore, that a further increase in the length of the alkyl group beyond eight carbon atoms does not produce any additional steric effect that can interfere with the molecular packing in the solid state, and indeed the constant melting point for the polymers with longer alkyl groups may be that resulting from the crystallization of the side chain alkyl groups themselves rather than the polymer main chains.

On the other hand, the clearing temperatures of the polymers in this series decreased steadily with increasing length of the substituent, although the contribution of each additional methylene unit to the depression of this transition temperature became smaller, as shown by the gradually decreased slope of the curve in Figure 1. This phenomena may be explained as the result of the gradually decreased contribution of each additional methylene unit to the molecular diameter (as defined by Gray ${ }^{15}$ ) of the mesogenic units. ${ }^{35}$

When the alkyl group was lengthened to more than 6 carbon atoms, the clearing temperature of this particular polymer series either may have been depressed so much that it was even lower than the melting point or the polymer was incapable of forming a liquid crystalline mesophase; such was apparently the case also for polymers with octyland decyl-substituents.

Because of the zig-zag manner of the change in the melting point and the steady decrease in the clearing temperature with increasing length of the alkyl groups, the temperature range of the stable mesophase of these alkyl-substituted polymers changed also in a nearly zig-zag fashion. As seen in Figure 1, the ethyl-substituted polymer had the lowest melting point $\left(71^{\circ} \mathrm{C}\right)$ and the widest mesophase range $\left(56^{\circ} \mathrm{C}\right)$. Hence, substituents can depress both the melting point and the isotropization temperature, but they do not necessarily narrow the temperature range of the stable mesophase, especially when the alkyl group is small.

\section{Pendant Polar Groups}

Substituents other than alkyl groups were also studied. ${ }^{36}$ It was found that highly polar substituents (e.g., $-\mathrm{CN},-\mathrm{NO}_{2}$ ), were very effective in depressing both the melting and clearing temperatures of these polymers. This depression may be again considered to be partly the result of the steric effects, which limited the molecular packing efficiency in both the crystal and the liquid crystal state, but some effect of the polarity of the group itself is believed to be important also, and the latter is believed to be the cause of the higher clearing temperatures of the bromo-, cyano- and nitrosubstituted polymers. These substituents are all larger in size than the methyl group, but the clearing temperatures of their polymers were found to be higher than those of the methyl-substituted polymer. The methoxy-substituted homopolymer in this series was found to be monotropic with a melting point of $158^{\circ} \mathrm{C}$.

\section{Chiral Flexible Units}

As expected from the known behavior of low molecular weight thermotropic compounds, the presence of a chiral flexible spacer in a thermotropic, main chain polymer can cause the formation of a cholesteric phase.

Strzelecki and coworkers ${ }^{27}$ found that the use of (+) 3-methyladipic acid as monomer for the preparation of liquid crystal polyesters gave homopolymers and copolymers capable of forming cholesteric phases on melting. The wavelength of iridescent light reflected by the copolymer melt increased as the content of the non-chiral spacers increased, indicating that the pitch spacing of the helical packing of the nematic layers increased accordingly. That is, this observation can be explained by the assumption that the molecular twist angle increased in a simple relationship to the amount of chiral spacers in the copolymer chain leading to a shorter pitch.

Blumstein and coworkers ${ }^{28,29}$ studied the cholesteric behavior of polyesters with azoxybenzene mesogenic units and the same chiral spacer, that from (+) 3-methyladipic acid. They could clearly observe oily streak textures, which are typical of low molecular weight cholesterics, for their homopolymers and copolymers. In contrast, a racemic mixture of the 3-methyladipic acid units in their polyester resulted in the formation of a nematic phase. Similar cholesteric polyesters based on azobenzene mesogenic units and $(+)$ 3-methyladipic acid were also reported by Iimura and coworkers, ${ }^{30}$ and Krigbaum and coworkers ${ }^{31}$ prepared cholesteric polyesters from the reaction of 4,4'-dihydroxy- $\alpha$ methylstilbene with mixtures of $(+)$ 3-methyladipic acid and adipic acid. They could change the mor- 


\section{R. W. LENZ}

phology of the cholesteric state formed by the $(+)$ 3-methyladipic acid homopolymer by mixing it either with a low molecular weight nematic compound or with a nematic polyester made from adipic acid. The 50:50 copolyester showed a predominately planar texture, which could be retained in the solid state by quenching. The quenched film maintained a deep blue color at room temperature.

Three series of cholesteric polyesters were recently prepared in our laboratory ${ }^{32}$ from either $(+)$ 3-methyladipic acid or (+) 3-methyl-1,6-hexanediol with the following structures:

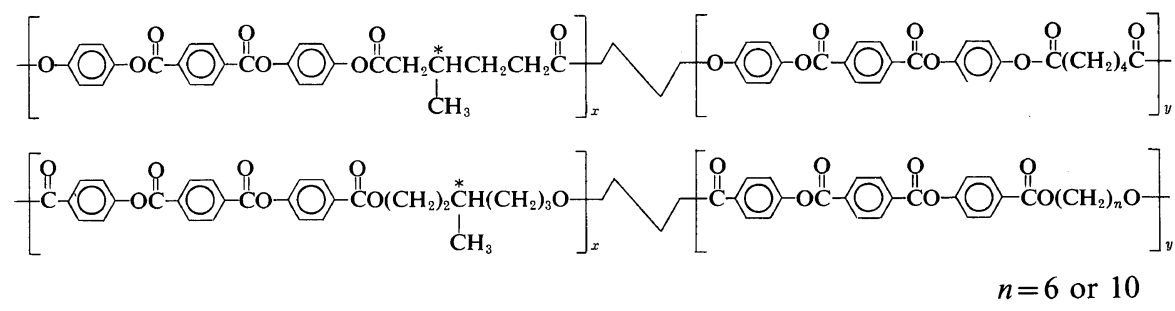

Cholesteric oily streak textures could again be clearly observed for these thermotropic polymers and copolymers containing chiral spacers. In general, the pitch of the helical packing increased in a regular manner not only with temperature, as judged by an iridescent color, but also with the amount of achiral component in the copolymers.

\section{EFFECTS OF MESOGENIC UNITS ON THERMOTROPIC PROPERTIES}

The variations which occur in the structureproperty relationships of thermotropic, main chain polyesters as a function of the structure of the mesogenic units have been studied extensively for the effect of three different types of modifications of their chemical structure, including changes in (1) structural units, (2) length of mesogen and its aspect ratio (length-to-width ratio), and (3) the presence of lateral substituents, generally in a random head-totail, head-to-head orientation along the chain. It has been found in this and other laboratories that even a slight change in the chemical structure of the mesogenic groups can result in a significant change in the thermal properties of the mesophase.

\section{Structural Unit Effects}

The types of profound changes which can result from relatively small changes in the mesogenic group structure are demonstrated in a comparison of the liquid crystal-to-isotropic phase transition temperature (the clearing temperature), $T_{\mathrm{i}}$, of the first three polymers in Table III. ${ }^{4,10,37}$ These polymers contain three different but closely related aromatic ester triad mesogens connected by a common flexible spacer, the decamethylene group. The major difference between the three polymers is in the specific structure of the central aromatic ester of the mesogenic units. Polymer A has a central hydroquinone residue while Polymers $\mathrm{B}$ and $\mathrm{C}$ have central terephthaloyl residues.

As seen in Table III, $T_{\mathrm{i}}$ for Polymer A is significantly higher than those of either Polymers B or C, indicating a greater thermal stability of the liquid crystal phase of the former. This observation can be explained on the basis of an expected coplanar and colinear geometry of the mesogenic units of Polymer A, in contrast to the non-linear conformation resulting from the presence of a central terephthaloyl moiety in the other two, as has been previously suggested for low molecular liquid crystal compounds. ${ }^{38} \mathrm{~A}$ coplanar molecular geometry favors a more effective molecular packing and alignment between the polymer molecules in the liquid crystal phase, which in turn stabilizes the mesophase. ${ }^{39}$

The slightly higher thermal stability of the mesophase of Polymer C over that of Polymer B is understandable because the mesogenic unit/in Polymer $\mathrm{C}$ is further extended through the terminal carbonyl groups, which are in resonance interaction with the neighboring phenyl rings. Even though this effect would seem to be minor, the presence of the two terminal carbonyl groups enables the formation of a smectic phase in Polymer C, while the other two polymers, $\mathrm{A}$ and $\mathrm{B}$, form nematic phases.

Increasing the length of the linear rigid mesogenic unit also enhances the thermal stability of the 
Table III. Thermal of liquid crystal polyesters with different mesogenic units

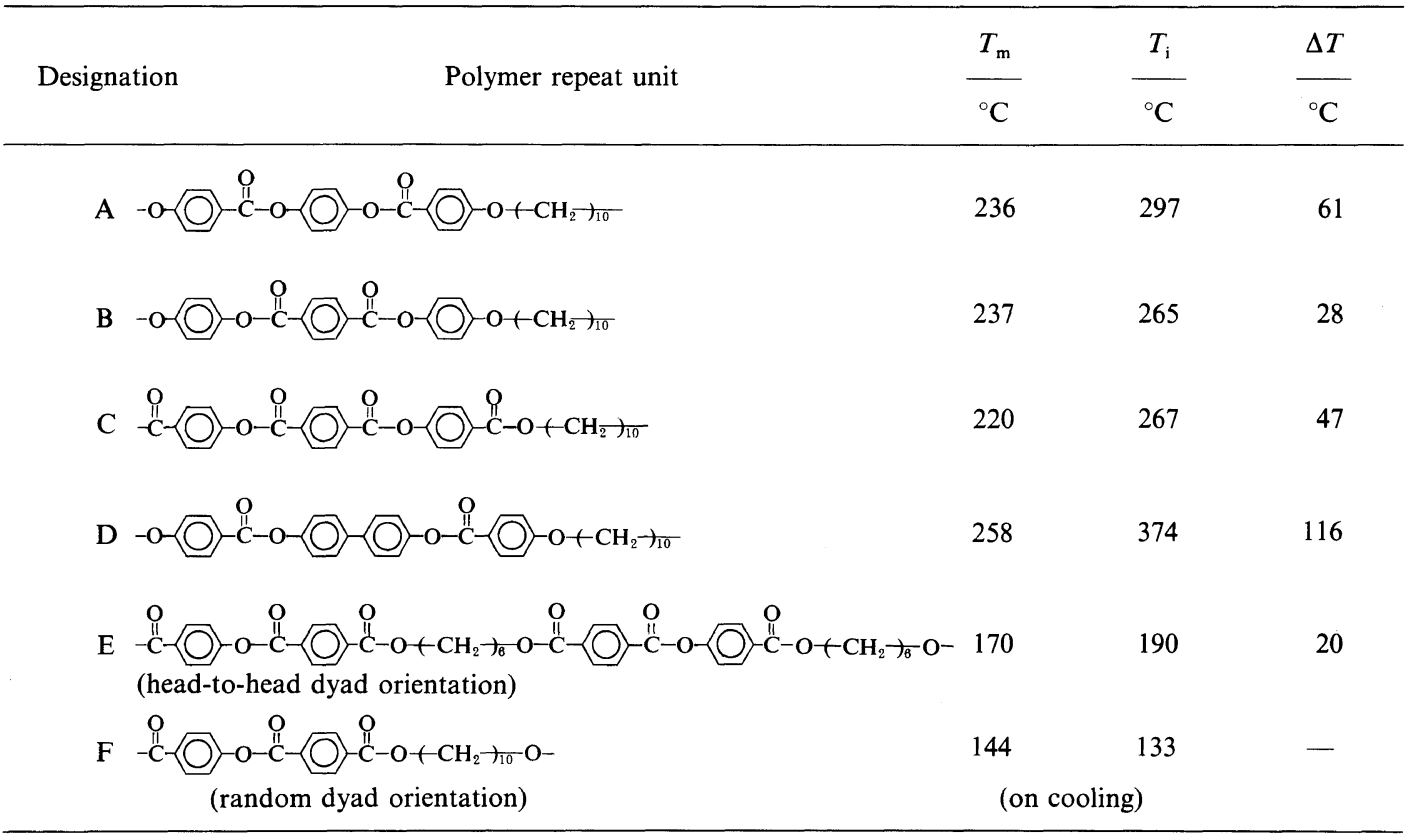

Table IV. Effect of lateral substituents on the liquid crystal properties of main chain polyesters

\begin{tabular}{|c|c|c|c|c|c|c|c|}
\hline \multirow{2}{*}{ Designation } & \multicolumn{2}{|c|}{ Polymer repeat unit } & \multirow{2}{*}{$\frac{T_{\mathrm{m}}}{{ }^{\circ} \mathrm{C}}$} & \multirow{2}{*}{$\frac{T_{\mathrm{i}}}{{ }^{\circ} \mathrm{C}}$} & \multirow{2}{*}{$\frac{\Delta T}{{ }^{\circ} \mathrm{C}}$} & \multirow{2}{*}{$\frac{\Delta H_{\mathrm{i}}}{\mathrm{kcal} \mathrm{mol}^{-1}}$} & \multirow{2}{*}{$\begin{array}{l}\Delta S_{\mathrm{i}} \\
\text { e.u. }\end{array}$} \\
\hline & $\mathrm{X}$ & $\mathrm{Y}$ & & & & & \\
\hline A & $\mathbf{H}$ & $\mathrm{H}$ & 236 & 297 & 61 & 0.97 & 1.7 \\
\hline A-1 & $\mathrm{H}$ & $\mathrm{Cl}$ & 157 & 279 & 122 & 2.5 & 4.6 \\
\hline A-2 & $\mathbf{H}$ & $\mathrm{CH}_{3}$ & 162 & 274 & 112 & 7.6 & 2.9 \\
\hline A-3 & $\mathrm{H}$ & $\mathrm{Br}$ & 146 & 270 & 124 & 2.8 & 5.2 \\
\hline A-4 & $\mathbf{H}$ & $\mathrm{C}_{6} \mathrm{H}_{5}$ & 151 & 168 & 117 & 1.6 & 3.6 \\
\hline A-5 & $\mathrm{Cl}$ & $\mathrm{Cl}$ & 200 & 255 & 55 & 0.94 & 1.8 \\
\hline
\end{tabular}

mesophase as shown by a comparison of the properties of Polymers A and D in Table III. ${ }^{44}$ The replacement of the middle $p$-phenylene unit in Polymer A with the biphenylene unit is accompanied by an increase in $T_{\mathrm{i}}$ of about $80^{\circ} \mathrm{C}$ and a much greater thermal stability of the mesophase. Similarly, on shortening the mesogenic unit the thermal stability of the liquid crystal phase decreases, as seen in a comparison of the data for Polymers A and E in Table III; ${ }^{10}$ that is, for triad compared to dyad units, respectively. Furthermore, if a longer spacer is inserted into a dyad polyester of the structure of Polymer E in Table III, in which the dyad units are also arranged in a random head-tail orientation, the stability of the nematic phase is decreased to the point that $T_{\mathrm{i}}$ is below $T_{\mathrm{m}}$, and the liquid crystalline phase can only be observed on cooling of the isotropic melt. That is, the polymer is monotropic. $^{42}$

In addition to these structural factors, the pres- 
ence of lateral substituents in the mesogenic units also plays a very important role in controlling the thermal behavior of the mesophase of the main chain polymers as was described earlier for the alkylhydroquinone terephthalate polymers. In our investigation of these triad ester polymers, we have also systematically varied the lateral substituent on the middle $p$-phenylene ring of the mesogenic unit of Polymer A of Table III, and the properties of these polymers are tabulated in Table IV. ${ }^{10,37}$ The data in Table IV can be summarized as follows: (1) monosubstitution decreases $T_{\mathrm{i}}$ and the thermal stability of the mesophase, (2) the degree of reduction in $T_{\mathrm{i}}$ by a substituent is directly related to its size, (3) the presence of two substituents of the same type, as in Polymer A-5 in Table IV, lowers $T_{\mathrm{i}}$ approximately twice as much as one indicating the possible existence of additivity in substituent effect (however, $T_{\mathrm{m}}$ is increased, so the effect on $\Delta T$ is even greater), and (4) polymers based on a monosubstituted hydroquinone unit, as Polymers A-1 through A-4 in Table IV, exhibit higher values of $\Delta S_{\mathrm{i}}$ than those with an unsubstituted (Polymer A) or a symmetrically disubstituted unit (Polymer A5).

All of these observations can be rationalized on the basis of either of two effects, either (1) steric hindrance by the substituents causes an increased separation of the mesogenic units in adjacent polymer chains or (2) an interlocking by the substituent on adjacent chains decreases molecular mobility in the liquid crystal phase. ${ }^{37}$ The former decreases $T_{\mathrm{i}}$ while the latter increases $\Delta S_{\mathrm{j}}$ as can be seen in Tabel IV. Polar effects do not seem to exert an important role on the thermal stability of the mesophases of these polymers, in contrast to those discussed previously.

With the exception of Polymer C, which formed a smectic phase on melting, all of the polymers in Tables III and IV exhibited only a nematic liquid crystal phase. The formation of liquid crystal phases by all of the polymers was reversible; that is, they are all enantiotropic. In general, super-cooling during reformation of the liquid crystal phase from the isotropic phase was much less pronounced than that for recrystallization, and this effect readily permitted the observation of monotropic behavior in Polymer F of Table III.

\section{Non-Mesogenic Rigid Spacer Effects}

The types of rigid non-mesogenic spacers which we have used to modify and control the thermal properties of thermotropic copolyesters are those based on bisphenols containing different central substituents between the two phenolic rings, $\mathrm{HO}-\mathrm{O}-\mathrm{X}-\mathrm{O}-\mathrm{OH}$, in which $\mathrm{X}$ is either $\mathrm{C}\left(\mathrm{CH}_{3}\right)_{2}$, $\mathrm{CH}_{2}, \mathrm{O}, \mathrm{S}$ or $\mathrm{SO}_{2}$. Resorcinol was also included in this series. For each of these non-mesogenic unit monomers, a series of copolyesters based on $o$ chloro- $p$-phenylene terephthalate, $\mathrm{CHQ}$, and the respective bisphenol terephthalate units were prepared over a wide range of comonomer compositions. For each series, the maximum or threshold amount of each bisphenol comonomer which could be incorporated into the random copolymers without complete destruction of the liquid crystal nature of the resulting copolymers was determined, with the results shown in Table V. ${ }^{37,40}$ All of the liquid crystal copolymers formed nematic phases.

The results collected in Table $\mathrm{V}$ clearly demonstrate that the greater the bulkiness of the central substituent, $\mathrm{X}$, in the rigid bisphenol spacer unit, the lower the threshold comonomer amount which could be accommodated in the copolymer without completely losing the liquid crystal characteristics. The differences in nonlinearity of the nonmesogenic units caused by the presence of the middle substituents of the bisphenols were all within about a $5^{\circ}$ angle of each other, indicating that the degree of intramolecular bending caused by $\mathrm{X}$ was approximately the same.

Table V. Maximum amount of each bisphenol monomer which could be copolymerized without complete destruction of the liquid crystallinity of the CHQ copolyester

\begin{tabular}{lc}
\multicolumn{2}{c}{$\mathrm{MO}-\mathrm{X}-\mathrm{O}-\mathrm{OH}$} \\
& \multicolumn{2}{c}{$\mathrm{mol} \%$} \\
\hline & 40 \\
$\mathrm{C}\left(\mathrm{CH}_{3}\right)_{2}$ & 50 \\
$\mathrm{SO}_{2}$ & 60 \\
$\mathrm{CH}_{2}$ & 60 \\
$\mathrm{~S}$ & 70 \\
$\mathrm{O}$ & 60 \\
Resorcinol &
\end{tabular}


Certainly the larger $\mathrm{X}$ groups, for example the $\mathrm{C}\left(\mathrm{CH}_{3}\right)_{2}$ and $\mathrm{SO}_{2}$ groups, will also cause an increased separation of the adjacent polymer chains to further destabilize the mesophase, and both the stereogeometry or space-filling characteristics of the polymer units and the bulkiness of $\mathrm{X}$ must contribute to destabilizing the liquid crystal phase of these copolyesters. Conversely, the electronic or polar effects of the $\mathrm{X}$ groups on the liquid crystal properties were not as evident as the steric effects and can be considered to be relatively minor in comparison.

The copolymers of CHQ and resorcinol were unique in that the resorcinol unit did not have a central substituent, $\mathrm{X}$, as in the other bisphenols. This unit was able to maintain the rigidity of the polymer chain, but it induced a bend angle of $120^{\circ}$ along the polymer backbone, destroying the linearity and reducing the parallel association of polymer chains in the nematic state, thereby de- creasing the stability of mesophase. Jackson and coworkers earlier arrived at the same conclusion from their study on the liquid crystal properties of polyesters based on p-oxybenzoate modified poly(ethylene terephthalate). ${ }^{41}$ Unfortunately, in our studies, information on the clearing transitions of the liquid crystal phases could not be obtained because all of the polymers underwent thermal degradation before reaching the $T_{\mathrm{i}}$ transition.

\section{Copolymers with Flexible Spacers}

In addition to these types of rigid-rod polymers in which non-linear rigid units were inserted to reduce the aspect ratio of the mesogenic unit sequences, we have also prepared a series of random copolymers containing both linear mesogenic groups and nonlinear non-mesogenic groups in units with a common decamethylene spacer, of the following

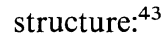

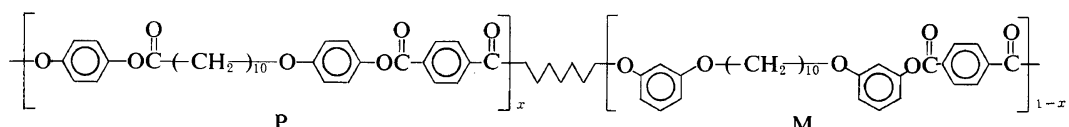

$$
\begin{aligned}
& \text { P } \\
& x=1.0,0.8,0.75,0.6,0.5
\end{aligned}
$$

As expected these copolyesters also showed regular decreases in all of their transition temperatures with decreasing $\mathrm{P}$ unit content, including $T_{\mathrm{m}}$ and $T_{\mathrm{i}}$ and their deisotropization, $T_{\mathrm{d}}$, and recrystallization, $T_{\mathrm{c}}$, temperatures as seen in the data in Table VI. The copolymer containing $60 \mathrm{~mol} \%$ of the mesogenic $\mathrm{P}$ unit was observed to form a barely visible nematic phase on melting on the hot stage of a polarizing microscope, but no clear $T_{\mathrm{i}}$ endotherm was found in its DSC endotherm. Even for the copolymer containing $75 \mathrm{~mol} \% \mathrm{P}$ units, the nematic phase which formed on melting contained many dark regions, which suggests that this type of mesogenic/non-mesogenic copolymer can form a two-phase melt which contains both liquid crystalline and isotropic regions in equilibrium. The relative amounts of bright and dark regions, and the birefringence intensities, observed for samples on the hot stage of a polarizing microscope, may be taken as an indication of the "degree of liquid crystallinity" (that is, the fractional amount of liquid crystalline phase) of the thermotropic melt, as we have suggested in an earlier report. ${ }^{40}$
The thermotropic melts of the copolymers containing $75 \mathrm{~mol} \%$ of $\mathrm{P}$ units or higher, and the $\mathrm{P}$ homopolymer, all showed strong opalescence on stirring their thermotropic melts, while that with 60 $\mathrm{mol} \%$ was only weakly opalescent, and the $50 \mathrm{~mol} \%$ copolymer showed no stir opalescence. ${ }^{40}$ Hence, this property may also indicate, in a semiquantitative manner, that either the amount or the stability of the liquid crystalline phase is directly related to the mesogenic-to-non-mesogenic unit ratio in the same manner as are the crystalline properties in a copolymer. Previous experience in this laboratory with a variety of aromatic polyesters suggests that a polymer must contain no less than $50-60 \mathrm{wt} \%$ mesogenic units to be able to form a stable thermotropic mesophase. ${ }^{34,40}$

A more quantitative indication of the "degree of liquid crystallinity" can be made from the area of the $T_{\mathrm{i}}$ endothermic peaks and the $T_{\mathrm{d}}$ exothermic peaks (see Table VI) in the DSC thermograms of these copolymers. That is, relative and very approximate estimates of either the amount or the stability of the nematic phase can be determined 


\section{R. W. LENZ}

Table VI. Thermal properties of polyesters and copolyesters with $\mathrm{P}$ and $\mathrm{M}$ units

\begin{tabular}{|c|c|c|c|c|c|c|}
\hline \multirow{2}{*}{\multicolumn{2}{|c|}{$\begin{array}{l}\text { Composition, unit } \\
\text { mole fractions }\end{array}$}} & \multirow{3}{*}{$\frac{\eta_{\mathrm{inh}}^{\mathrm{a}}}{\mathrm{dl} \mathrm{g}^{-1}}$} & \multicolumn{4}{|c|}{ Transition Temp $/{ }^{\circ} \mathrm{C}$} \\
\hline & & & \multicolumn{2}{|c|}{ Heating cycle } & \multicolumn{2}{|c|}{ Cooling cycle } \\
\hline $\mathbf{P}$ & $\mathbf{M}$ & & $T_{\mathrm{m}}$ & $T_{\mathrm{i}}$ & $T_{\mathrm{c}}$ & $T_{\mathrm{d}}$ \\
\hline 1.0 & 0 & 0.79 & 265 & 321 & 229 & 309 \\
\hline 0.80 & 0.20 & 0.67 & 238 & 274 & 208 & 270 \\
\hline 0.75 & 0.25 & 0.90 & 233 & 265 & 217 & 267 \\
\hline 0.60 & 0.40 & 1.0 & 230 & 242 & 215 & - \\
\hline 0.50 & 0.50 & 0.67 & 212 & - & 170 & - \\
\hline 0 & 1.0 & 0.21 & 108 & - & - & - \\
\hline
\end{tabular}

${ }^{\text {a }}$ Inherent viscosity of solutions in $p$-chlorophenol at a concentration of $0.2 \mathrm{~g} \mathrm{dl}^{-1}$ at $45 \pm 0.3^{\circ} \mathrm{C}$.

from these peak areas, and visual inspection of their thermograms revealed that even at $80 \mathrm{~mol} \%$ $\mathrm{P}$, this copolymer had a much smaller $T_{\mathrm{i}}$ endotherm compared to that of the homopolymer.

Acknowledgement. The author is grateful to the great many contributions of his coworkers listed in the literature references in this program and to the financial support of the National Science Foundation and the Office of Naval Research.

\section{REFERENCES}

1. P. J. Flory, Proc. R. Soc. London, Ser. A, 234, 73 (1956).

2. C. Robinson, Trans. Faraday Soc., 52, 571 (1956); Tetrahedron, 13, 219 (1961).

3. S. L. Kwolek, U.S. Patent 3,671,542 (1972).

4. J.-I. Jin, S. Antoun, C. Ober, and R. W. Lenz, Br. Polym. J., 12, 132 (1980)

5. A. Roviello and A. Sirigu, J. Polym. Sci., Polym. Lett., 13, 455 (1975).

6. W. J. Jackson and H. F. Kuhfuss, J. Polym. Sci., Polym. Chem. Ed., 14, 2043 (1976).

7. I. Goodman, J. F. McIntyre, and J. W. Stimpson, Br. Patent 989,552 (1965); I. Goodman, J. F. McIntyre, and D. H. Aldred, Br. Patent 993,272 (1965).

8. S. G. Cottis, J. Economy, and B. F. Nowak, U.S. Patent 3,637,595 (1972).

9. C. K. Ober, J.-I. Jin, Q. Zhou, and R. W. Lenz, Adv. Polym. Sci., 59, 104 (1984).

10. C. K. Ober, J.-I. Jin, and R. W. Lenz, Polym. J., 14, 9 (1982).

11. C. K. Ober, J.-I. Jin, and R. W. Lenz, Makromol. Chem., Rapid Commun., 4, 49 (1983).

12. R. W. Lenz and J.-I. Jin "Liquid Crystals and Ordered Fluids," A. Griffin and J. Johnsons, Ed.,
Plenum Press, New York, in print.

13. A. C. Griffin and S. J. Havens, J. Polym. Sci., Polym. Phys. Ed., 19, 951 (1981).

14. L. Strzelecki and D. van Luyen, Eur. Polym. J., 16, 299 (1980).

15. G. W. Gray and A. Mosley, J. Chem. Soc., Perkin Trans., 2, 97 (1976).

16. G. Galli, E. Chiellini, C. K. Ober, and R. W. Lenz, Makromol. Chem., 183, 2693 (1982).

17. A. Roviello and A. Sirigu, Makromol. Chem., 183, 895 (1982).

18. A. Blumstein and O. Thomas, Macromolecules, in press.

19. K. Iimura, N. Koide, R. Ohta, and M. Takeda, Makromol. Chem., 182, 2563 (1981).

20. W. H. de Jen, J. van der Veen, and W. J. P. Goosens, Solid State Commun., 12, 405 (1973).

21. H. Stenschke, Solid State Commun., 10, 653 (1972).

22. G. W. Gray, J. Phys. (Paris), 36, 337 (1975).

23. G. W. Gray and K. J. Harrisen, Symp. Faraday Soc., 5, 54 (1971).

24. A. Pines, D. J. Ruben, and S. Allison, Phys. Rev. Lett., 33, 1002 (1974).

25. S. Marcelja, J. Chem. Phys., 60, 3599 (1974); D. A. Pink, J. Chem. Phys., 63, 2533 (1975).

26. W. Maier and A. Saupe, Z. Naturforschg., 149, 882 (1959).

27. D. van Luyen, L. Liebert, and L. Strzelecki, Eur. Polym. J., 16, 307 (1980).

28. A. Blumstein and S. Vilasagar, Mol. Cryst. Liq. Cryst. Lett., 72, 1 (1981).

29. A. Blumstein, S. Vilasagar, S. Ponrathnan, S. B. Clough, and R. B. Blumstein, J. Polym. Sci., Polym. Phys. Ed., 20, 877 (1982).

30. K. Iimura, N. Koide, Y. Tsutsumi, and $\mathbf{M}$. Nakatami, Rep. Prog. Polym. Phys. (Jpn), 25, III-1 (1982).

31. W. R. Krigbaum, A. Ciferri, J. Asrar, and H. Toriumi, Mol. Cryst. Liq. Cryst., 76, 79 (1981). 
32. J.-I. Jin, H. Park, and R. W. Lenz, "Synthesis and Properties of New Cholesteric Main Chain Polyesters," presented at IXth International Conference on Liquid Crystals, Bangalore, India, Dec. 6-10, 1982.

33. J. Majnusz, J. M. Catala, and R. W. Lenz, Eur. Polym. J., 19, 1043 (1983).

34. Q. Zhou and R. W. Lenz, J. Polym. Sci., Polym. Chem. Ed., 21, 3313 (1983).

35. L. Strzelecki and L. Liebert, Eur. Polym. J., 12, 1271 (1981).

36. Q. F. Zhou, R. W. Lenz, and J.-I. Jin, J. Polym. Sci., Polym. Chem. Ed., in press.

37. S. Antoun, R. W. Lenz, and J.-I. Jin, J. Polym. Sci. Polym. Chem. Ed., 19, 1901 (1981).
38. M. J. S. Dewar and R. M. Riddle, J. Am. Chem. Soc., 97, 6658 (1975).

39. G. R. Luckhurst and G. W. Gray, eds, "The Molecular Physics of Liquid Crystals," Academic Press, New York, 1979, p 15 and references cited therein.

40. R. W. Lenz and J.-I. Jin, Macromolecules, 14, 1405 (1981).

41. W. J. Jackson, Jr., Br. Polym. J., 12, 154 (1980).

42. C. Ober, R. W. Lenz, G. Galli, and E. Chiellini, Macromolecules, 16, 1034 (1983).

43. G. Chen and R. W. Lenz, J. Polym. Sci., Polym. Chem. Ed., in press.

44. B.-W. Jo, J.-I. Jin, and R. W. Lenz, Makromol. Chem., Rapid Commun., 3, 23 (1982). 